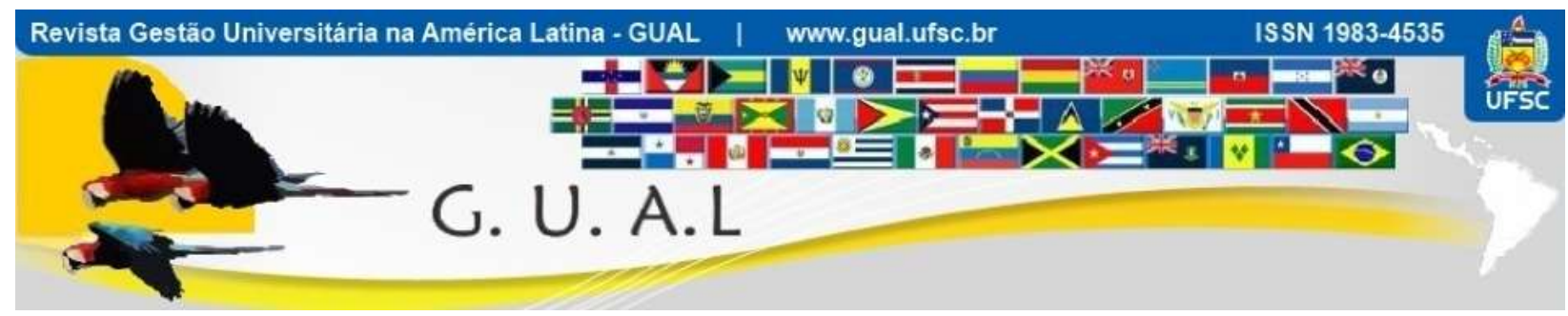

DOI: http://dx.doi.org/10.5007/1983-4535.2020v13n2p49

\title{
ENSINO-APRENDIZAGEM EM CIÊNCIAS SOCIAIS APLICADAS: UM ESTUDO SOBRE EDUCAÇÃO INCLUSIVA NA UNIVERSIDADE
}

\section{TEACHING-LEARNING IN APPLIED SOCIAL SCIENCES: A STUDY ON INCLUSIVE EDUCATION AT UNIVERSITY}

\author{
Suzete Antonieta Lizote, Doutora \\ https://orcid.org/0000-0003-3575-1675 \\ lizote@univali.br \\ Universidade do Vale do Itajaí | Programa de Pós-Graduação em Administração \\ Biguaçu | Santa Catarina | Brasil \\ Claudia Silva Ribeiro Alves, Mestre \\ https://orcid.org/0000-0001-5257-4389 \\ dinha.csra@gmail.com \\ Universidade do Vale do Itajaí | Programa de Pós-Graduação em Administração \\ Biguaçu | Santa Catarina | Brasil
}

Sayonara de Fátima Teston, Doutora https://orcid.org/0000-0002-2469-1497 sayonara.teston@unoesc.edu.br Universidade do Oeste de Santa Catarina | Programa de Pós-Graduação em Administração Chapecó | Santa Catarina | Brasil

Recebido em 04/abril/2019

Aprovado em 07/fevereiro/2020

Publicado em 01/maio/2020

Sistema de Avaliação: Double Blind Review

Esta obra está sob uma Licença Creative Commons Atribuição-Uso. 


\title{
RESUMO
}

Este estudo analisa o processo de ensino aprendizagem de alunos deficientes auditivos em um curso de graduação em Administração. Para atender ao objetivo se optou por uma abordagem qualitativa, realizando sete entrevistas em profundidade, quatro com professores do curso de Administração que ministraram aulas para turmas onde participaram alunos com deficiências auditivas. Um deles foi orientador do trabalho de conclusão de curso, no qual o graduando desenvolve uma pesquisa científica. Entrevistou-se também a orientadora pedagógica do Centro de Ciências Sociais Aplicadas, que abriga esse curso, a um dos intérpretes que participou como mediador no curso escolhido para desenvolver esta pesquisa, e a um aluno surdo que se graduou em 2016. Os resultados indicam que todos efetuaram adaptações no plano de ensino. Nos procedimentos didáticos, as modificações tiveram maiores divergências, associando-se à criatividade. Quanto às avaliações, ocorrem diferenças nas provas e na participação dos intérpretes durante sua execução. As orientações pedagógicas caracterizam se como procedimentais. Conclui-se que o atendimento à legislação é parcial e sugerem-se ações para melhorar essa situação.

Palavras-chave: Formação Universitária. Incapacidade Auditiva. Educação Inclusiva.

\begin{abstract}
This study analyzes the process of teaching learning of hearing impaired students in an undergraduate course in Administration. In order to meet the objective, a qualitative approach was chosen, performing seven in-depth interviews, four with teachers from the Administration course who taught classes for students with hearing impairments. One of them was the supervisor of the course work, in which the graduate develops a scientific research. The pedagogical guide of the Center for Applied Social Sciences, who hosts this course, was also interviewed, one of the interpreters who participated as a mediator in the course chosen to develop this research, and a deaf student who graduated in 2016. The results indicate that all made adaptations in the teaching plan. In the didactic procedures, the modifications had greater divergences, being associated to the creativity. As for evaluations, there are differences in the evidence and in the participation of the interpreters during their execution. The pedagogical guidelines are characterized as procedural. It is concluded that compliance with the legislation is partial and actions are suggested to improve this situation.
\end{abstract}

Keywords: University Education. Hearing Impairment. Inclusive Education. 


\section{INTRODUÇÃO}

A relevância e a importância do tema da educação inclusiva abrange o mundo. Há uma consciência global do valor da sua construção para o desenvolvimento social e econômico de um país. E, a partir desta constatação têm sido realizadas ações governamentais mundiais, com políticas públicas que têm demonstrado sensibilidade e ações concretas sobre o tema.

Educação inclusiva implica em que todos os educandos de uma determinada comunidade estudem juntos, independentemente de suas condições pessoais. A inclusão de indivíduos portadores de necessidades educativas especiais é um desafio que foi formalmente reconhecido em nível global na última década do século $\mathrm{XX}$.

O termo educação inclusiva ganhou maior significado a partir da Declaração de Salamanca (MEC, 2011), em junho de 1994, quando representantes de 92 países e 25 organizações internacionais tornaram oficial a "Educação para Todos". Esta, segundo Bueno (2001), foi baseada em dois fatores extremamente importantes: 1) a perspectiva política da construção de um sistema escolar de qualidade para todos; e, 2) a constatação de que qualquer educando possui características, interesses, habilidades e necessidades únicas e que, portanto, a escola precisa adequar-se a elas. Em 2006, na Organização das Nações Unidas foi estabelecida a Convenção sobre os Direitos das Pessoas com Deficiências (ONU, 2011), que no artigo 24, refere-se à educação, e no inciso 5 trata do direito ao ensino superior.

Neste ponto cabe ressaltar a importância das instituições e dentre elas a universidade pode e deve atuar face seu grande compromisso com a sociedade, particularmente, por ser nela onde se formam os professores de todos os níveis da educação formal. Pois se deve considerar à educação protagonista para a construção da cidadania e o desenvolvimento da sociedade.

A política educacional no Brasil tem a finalidade de viabilizar uma educação integradora, isto é, uma educação organizada de forma a atender a todos, incluindo os portadores de necessidades especiais (ALENCAR, 1994). A Lei de Diretrizes e Bases da Educação Nacional, Lei Federal no 9.394, de 20 de dezembro de 1996, (BRASIL, 1996) obriga todas as instituições de ensino, seja fundamental, médio ou superior, a receberem como alunos regulares os indivíduos portadores de necessidades especiais, incluindo as auditivas. Preceitua o artigo 59 da referida Lei, que os sistemas de ensino devem possuir uma organização de trabalho pedagógico que permita atender às necessidades específicas, assim como professores preparados e capacitados para integrar os estudantes portadores de 
necessidades especiais nas classes comuns. Quanto à educação superior o artigo 44 da Lei 9.394, assim como o artigo 27 do Decreto Federal 3.298 de 20 de dezembro de 1999 (BRASIL, 1999) asseguram esse direito em todos os tipos de cursos e níveis, desde que atendidos os requisitos próprios do ingresso de acordo com a instituição, seja pública ou privada.

A presença do aluno surdo no sistema educacional é sem dúvida, um importante instrumento de ampliação do seu espaço de participação social. É preciso garantir, entretanto, oportunidades de experiências, de aprendizagens e de estratégias criativas de ensino para que possa ter êxito nos seus estudos e na sociedade. Sendo a educação para a ciência parte do processo formativo do aluno universitário, induzindo-lhe a criar conhecimento, uma das funções precípuas da universidade.

Desta forma, conforme orientam Teodoro e Vasconcelos (2003), é necessário estar atento para os aspectos da prática pedagógica no cotidiano universitário que revelem como está ocorrendo o processo de ensino-aprendizagem, de modo que se tenham condições de avaliar os pontos positivos e negativos que nortearão, além da própria prática formativa, as questões ligadas à inclusão.

Diante deste contexto, o estudo tem como objetivo analisar o processo de ensino aprendizagem de alunos deficientes auditivos em um curso de graduação em Administração. Buscou-se, portanto, analisar alguns aspectos do processo ensino-aprendizagem na universidade para alunos com necessidades especiais auditivas, relacionando-os com a criatividade dos professores e as orientações por eles recebidas dos órgãos institucionais competentes no sentido de poder satisfazer os preceitos legais e a formação acadêmica do educando. Ou seja, explorar-se-ão as diversas formas de interações entre professores e alunos, no intuito de contribuir para o desenvolvimento de uma educação apropriada e que valorize a diversidade. Especialmente as variadas formas de comunicação, haja vista que ela é fundamental à aprendizagem, pois o conhecimento adquirido em resposta ao processo de ensino depende tanto da comunicação didática quanto da própria auto formação do aluno (HERRÁN, 2010).

Destaca-se que na universidade são formados os professores que atenderão o ensino em todos os níveis e, por consequência, a educação para a ciência vincula-se necessariamente ao ensino superior. Isto é, sob esta ótica educação para ciência equivale a formar um aluno 
para que possa criar conhecimento. Que tenha possibilidade de desenvolver um projeto inovativo na área de sua graduação ou profissão, independente de ser deficiente ou não.

\section{EDUCAÇÃO INCLUSIVA NO ENSINO SUPERIOR}

A educação inclusiva na concepção de Lacerda e Poletti (2004) busca responder às necessidades de aprendizagem das crianças, jovens e adultos, focando especificamente naqueles que estão vulneráveis à marginalização e à exclusão. Nesta perspectiva, Botelho (2002) entende que o desenvolvimento de sistemas educacionais inclusivos, que se propõem a acolher todos os indivíduos, independente de suas condições sociais, intelectuais, emocionais, entre outras, representam a possibilidade de eliminar a exclusão e responder as expectativas e especificidades de cada um.

Cardoso (2001) coloca que há uma tendência da sociedade em normalizar, disciplinar ou excluir aqueles que são denominados especiais. A surdez possui uma equivocada tradição histórica, quando eram vistos como doentes, alienados e privados de toda e qualquer possibilidade de desenvolvimento intelectual e moral. Os primeiros registros de educação para surdos no Brasil datam de 1876, quando o imperador D. Pedro II contratou o Professor francês surdo Hernest Huet para fundar o Instituto Nacional de Educação de Surdos (INES), primeira escola desse tipo no país.

As diretrizes das novas políticas educacionais promoveram a discussão e o avanço sobre a educação de surdos no Brasil e têm se constituído em um desafio teórico e pedagógico na atualidade. Soares (1999) comenta que a educação de surdos considera como principal objetivo a capacitação do aluno para adquirir um código linguístico e fornecer certa instrumentalização para o trabalho, mesmo afirmando que a surdez não se constitui em um fator de impedimento para a aquisição do conhecimento e que o currículo pode ser o mesmo utilizado na educação comum, exigindo somente adaptações.

Neste contexto, para que tais finalidades sejam alcançadas, segundo Giordani (2002), é necessário um novo olhar acerca do exercício da docência no ensino superior, visto que os "objetos" do trabalho do professor são os indivíduos: seus saberes, habilidades e competências. Assim como, tratar de perceber o ensino como atividade psíquica de formação e construção de inteligências.

No que tange a educação inclusiva, Bueno (2001) salienta a importância do reconhecimento da língua brasileira de sinais (Libras), oficialmente adotada como meio legal de comunicação e expressão pela Lei Federal 10.436 de 24 de abril de 2002 (BRASIL, 2002), assim 
como a extremada importância de sua utilização para a educação de deficientes auditivos. Por outro lado, este tema tem sido, de certa forma, polêmico sob vários prismas, desde o tipo de comunicação mais adequado a ser utilizado até a capacitação dos professores. É importante enfatizar que somente em 2001 o Ministério da Educação passou a oferecer cursos de Libras para os professores. Essa língua conforme Brito (1995) é considerada uma linguagem natural, pois surgiu espontaneamente por meio de interações entre pessoas e permite a expressão de qualquer conceito descritivo, emotivo, racional, literal, metafórico, concreto ou abstrato.

Desta forma, um dos tópicos que surgem como extremamente importantes à discussão está relacionado à perspectiva teórico-metodológica adotada, referenciando o desenvolvimento do processo de mediação entre o aluno surdo e os conceitos sistematizados no ensino superior por meio do intérprete, quem deve imprimir uma comunicação didática motivadora através da língua de sinais.

O intérprete ou mediador, como enfatiza Quadros (1995), processa a informação da língua-fonte e faz escolhas lexicais, estruturais, semânticas e pragmáticas na língua alvo que se vem a aproximar o mais apropriadamente possível do conteúdo dado. Sua participação é fundamental no aspecto metodológico, pois esse profissional tem a responsabilidade da transferência dos conteúdos. Entretanto, para Lacerda e Poletti (2004) a presença do intérprete em sala de aula e o uso de Libras, não são garantias do êxito nas atividades pedagógicas, sugerindo, desta forma, maior atenção por parte das instituições quanto à metodologia utilizada e currículo proposto, uma vez que, dependendo daquela ou do tema selecionado, o mediador pouco ou nada pode fazer para favorecer a aprendizagem do aluno surdo.

\section{MATERIAL E MÉTODO}

O presente estudo foi desenvolvido numa instituição de ensino superior no Estado de Santa Catarina, Brasil, que se caracteriza como universidade pública de direito privado, comunitária, filantrópica e sem fins lucrativos. Escolheu-se o curso de Administração, lotado no Centro de Ciências Sociais Aplicadas, onde existia no momento inicial do levantamento de dados uma situação pouco frequente, em que três alunos surdos cursavam uma mesma disciplina. O trabalho de campo desenvolveu-se entre 2017 e 2018.

A pesquisa teve como referencial os pressupostos da abordagem qualitativa. Godoy (1995) evidencia que os trabalhos qualitativos têm como preocupação fundamental o estudo e análise do mundo empírico em seu ambiente natural. Segundo Bauer (2002) a abordagem qualitativa busca descobrir como as noções se instalam, qual a qualidade dos processos 
interativos e como um fato singular pode adquirir relevância em relação aos contextos mais amplos. Ainda pressupõe o questionamento dos fenômenos e sujeitos investigados, com o objetivo de perceber aquilo que eles experimentam em suas instituições, o modo como interpretam as experiências e como estruturam o mundo social em que vivem.

A estratégia qualitativa utilizada coincide com o mencionado por Merriam (1998), pois foi uma pequena amostra não escolhida ao acaso, conformando um desenho flexível da pesquisa, com obtenção de dados primários para desenvolver conclusões compreensivas e descritivas. Assim, o material empírico foi obtido através de entrevistas semiestruturadas, as quais foram gravadas e posteriormente transcritas para serem analisadas. Anterior às gravações, foi explicado para os respondentes os objetivos da pesquisa e solicitado que assinassem o termo de consentimento livre e esclarecido. Por sua parte, o modelo de roteiro da entrevista foi submetido à avaliação de uma especialista com vasta experiência docente e administrativa.

O tratamento dos dados pautou-se em princípios da pesquisa qualitativa, balizados por indicativos da análise do discurso (MAINGUENEAU, 2008).

\section{RESULTADOS E DISCUSSÕES}

$\mathrm{Na}$ fase de classificação dos dados, no processo metodológico da pesquisa qualitativa, Oliveira (2007) afirma que são definidas categorias empíricas, as quais se originam dos tópicos das entrevistas e de cada questão elaborada e aplicada na pesquisa de campo. Segundo a autora, as respostas obtidas devem ser classificadas criteriosamente, observando-se as respostas similares ou convergentes para se definirem as unidades de análise que são trabalhadas à luz do referencial teórico.

Desta forma, para análise dos dados, definiram-se quatro eixos temáticos ou tópicos que estiveram contemplados no roteiro das entrevistas semiestruturadas. Estas dimensões configuraram-se como norteadores para a reflexão sobre o processo de ensino-aprendizagem em Ciências Sociais Aplicadas, desenvolvido em aulas universitárias para alunos com necessidades especiais auditivas, as quais são: plano de ensino, procedimentos didáticos, avaliação e orientações pedagógicas.

Ressalta-se que se optou, neste artigo, em situar as falas dos entrevistados nos aspectos teóricos abordados na pesquisa e, para fins de organização, os professores foram identificados 
como P1, P2, P3 e P4, a orientadora pedagógica como OP, ao aluno surdo graduado AG e o intérprete como IN.

\subsection{PLANO DE ENSINO}

O planejamento de ensino deve refletir os melhores meios de cultivar o desenvolvimento da ação escolar, envolvendo, sempre, todos os elementos participantes do processo. Quando interrogados sobre possíveis alterações em seus planos de ensino em função de ter alunos com deficiências auditivas, P4 com relação a disciplina Plano de Estágio disse:

Ele [o aluno graduado] desenvolveu o estágio da mesma forma que os alunos sem deficiência. Ele passou por todas as etapas, elaboração de questionário, entrevista com o dono da empresa, sem nenhuma alteração por ele ter a limitação auditiva, fez tudo igual aos demais.

P1, por sua vez, a respeito do seu plano de ensino expressou:

Só porque tem uma certa, uma turma com um aluno com dificuldade especial, eu não acho que a turma toda deva ter menos qualidade nas aulas, certo? O plano eu continuo o mesmo. Porque se eu mudar o conteúdo, o que né, vai acontecer? As pessoas sem necessidade vão ficar com uma certa deficiência, vão ter o conteúdo em menor escala, vamos dizer que as outras turmas, né. (...) e daí se no semestre seguinte eles vão fazer um certo conteúdo com um outro professor ou sei lá, em outro período, o que vai acontecer? Ele vai ficar em defasagem aos que tiveram aula sem aquele aluno de necessidade especial.

Percebe-se desta forma, para que o professor possa planejar adequadamente sua tarefa e atender às necessidades do aluno, deve levar em consideração o conhecimento da realidade. Depreende-se do seu discurso que a visão de realidade se coaduna com suas próprias crenças e valores, no marco do contexto temporal em que a ação terá seu reflexo. De um modo similar, Borba e Luz (2002) entendem que planejar é uma operação mental a partir de uma situação problema: "Como dar esta aula?". Observando o depoimento de P2 notam-se as dificuldades encontradas para lidar com as diferenças e o que a inclusão representa:

Eventualmente eu fiz alterações, mas, mais voltadas para ele apenas, eu mudei o meu trabalho para ele apenas, eu não mudei o meu trabalho com relação aqueles 40 , eu mudei o meu trabalho com relação a ele então, o que aconteceu? Ah,. trabalhos que seriam individuais, numa produção de texto por exemplo, ele então, em sala de aula, ele não tendo o tradutor ou mesmo, tendo o tradutor, eh, ele, ele poderia fazer em dupla, ou ele poderia fazer em casa, não precisaria estar ali, certo? Mudanças neste sentido exigem conhecimento deste tipo de aluno e isto eu não tenho. 
Isto, sem dúvidas, significa um grande desafio para as instituições que estão sendo chamadas a planejar, dando atendimento ao princípio fundamental da educação inclusiva: que os alunos, sempre que possível, aprendam juntos, independentemente de suas dificuldades ou diferenças. Percebe-se uma adequação da fala do P2 à reação prevista que as diferenças feitas nas atividades possam gerar no interlocutor. Corrobora Cunha (1997) ao comentar que planejar, é uma previsão inteligente e bem calculada de todas as etapas que envolvem o trabalho docente e discente, de modo a tornar o ensino seguro e eficiente. A respeito das mudanças feitas, o terceiro respondente P3 falou que:

Não no plano, mas na forma de passar o assunto, de cobrar a matéria né e de explicar para aquela pessoa. E claro, sempre tem um trabalho diferente né, as vezes a gente não consegue imprimir o mesmo ritmo. Se a secretaria ou direção do curso nos informasse antes do início das aulas que teremos este tipo de aluno, poderíamos planejar atividades.

Observa-se assim que é extremamente problemático para os docentes propiciar as mudanças, pois não recebem com suficiente antecipação a informação de que na sua turma haverá algum discente com tal deficiência. Assim, P3, na sua polifonia discursiva, relata sua discordância quanto ao proceder dos órgãos superiores. Entretanto, Bordenave e Pereira (1995) ao se referir ao plano de ensino enfatizam que é um instrumento de trabalho que disciplina os esforços dos professores e alunos, no sentido de racionalizar as atividades de ensino e aprendizagem, mas que não deve ser compreendido como algo definitivo e imutável; como todo plano, ele é flexível e, por isso, pode sofrer alterações.

Planejamento de ensino por si só não constitui nenhuma fórmula mágica para resolver todos os problemas. $\mathrm{O}$ esforço do professor aliado a um adequado plano de ensino promove uma atmosfera de trabalho que se pode chamar de metódica, onde é viável reconhecer, e até prever, diferentes situações e, ainda, enfrentar circunstâncias extraordinárias com maior segurança.

\subsection{PROCEDIMENTOS DIDÁTICOS}

O planejamento do ensino, de acordo com as abordagens consideradas anteriormente, sempre será um desafio para todos aqueles envolvidos no processo educacional, na busca dos meios mais adequados à obtenção de melhores e maiores resultados. Os quais, segundo enfatiza Libâneo (1991), somente serão atingidos na medida em que o professor for 
acumulando e enriquecendo experiências, ao lidar com as situações concretas de ensino, aliados, de um lado às metodologias específicas das matérias e de outro aos conhecimentos dos processos didáticos. Sobre a didática desenvolvida em sala de aula P1 relata:

Vai alterando em função deles. Tem aulas, por exemplo, que eu dito as questões de matemática. Porque assim, a gente traz um planejamento, mas a turma é bem ágil, então acabou aquela aula planejada, daí você tem que colocar mais questões porque o tempo ainda permite, né? Eu trago as questões já digitadas [quando há alunos com deficiência auditiva], porque eles demoram muito para copiar, né? Pra todos. Não digo que é por causa deles. Eu trago para todos.

Diante desta fala, percebe-se a importância do professor ter uma visão ampla e profunda do contexto em que desenvolve sua atividade docente. A importância de aprender a refletir a partir desse contexto e saber escolher as alternativas mais adequadas para cada situação, como salientado por P4 que falou:

No começo do trabalho, eu tive que puxar muito ele, talvez isso também tenha sido, acredito que tenha sido um fator positivo eu tratar ele de forma parecida com um aluno sem limitação. Então, no começo eu acho que ele esperava que eu fosse ajudar ele de uma forma mais intensa. Mas quando ele percebeu que tava exigindo dele, que tava realmente querendo que ele produzisse, aí ele começou a ver que o processo de estágio era algo bastante sério e que ele ia ter que se virar [...].

As falas demonstram a prática de ações, que tem por objetivo a mudança de uma situação. Por sua vez, P1 ao tratar da criatividade comenta que para avançar nos conteúdos precisou ser muito criativa, particularmente numa disciplina em que teve três alunos surdos na turma: "Tive que usar técnicas diferenciadas para eles e para a turma, mas não alterei em nada o conteúdo, só a maneira de os desenvolver. Fui estudar um pouco de libras até para facilitar minha comunicação com eles."

Igualmente, com o material impresso teve que fazer mudanças para atender outras necessidades desses alunos, conforme se denota no seu discurso: "Como minha disciplina é cálculo, utilizo muitas tabelas e fórmulas. Para eles usei tabelas diferenciadas, mas sem alterar o conteúdo, só na forma de elaboração e na sequência lógica dos cálculos, porque percebo que eles sentem muita dificuldade na lógica, porque envolve muita interpretação $[\ldots] "$.

Enfatizam Bordenave e Pereira (1995) que o ensino, por mais simples que possa parecer à primeira vista, é uma atividade complexa, pois envolve tanto condições externas 
como internas das situações didáticas. Os professores, ao lecionar para alunos com deficiências auditivas precisam passar os conteúdos com clareza e simplicidade. O que se verifica na resposta de AG: "Os métodos e procedimentos passam as ideias do trabalho de forma simples e sem confusão. Ajuda muito a desenvolver o processo de estagio".

Conhecer bem as atividades e lidar acertadamente com elas é uma das tarefas básicas do professor para a condução do trabalho docente. P1 se coloca como responsável pelo que se diz, assumindo a autoria das mudanças didáticas. O respondente $\mathrm{P} 2$ em relação aos procedimentos didáticos comentou que:

Então, exatamente em termos de imagem, quando se usava imagem, é claro que estando ali o intérprete fica menos difícil para ele, certo? Mas que quando eu estava apresentando o trabalho para os 40, eu pensava nele, e, refletia: será que este aluno está entendendo o que eu estou falando? (...) Nas minhas aulas também, passo filmes. Tive que ter o cuidado para nesta turma passar o filme com legenda. Como minha disciplina é parte dela ministrada distância (4 encontros) algumas atividades tive que fazer de forma diferenciada para este aluno, pois tem que ter um detalhamento muito amplo na explicação da mesma para que ele compreenda o que está sendo postado e solicitado no Sophia."

O discurso de P2 evidencia o princípio do dialogismo, quando na sua fala conversa consigo nos seus questionamentos. Desta forma, observa-se que os grandes desafios impostos à pratica docente no ensino superior relacionam-se as duas ações didáticas: ensinar e aprender. Nesse esforço de articulação entre o ensino e a aprendizagem, Abreu e Masseto (1997) sinalizam para a necessidade atual de transposição de paradigmas na ação didática universitária: substituir a ênfase no ensino pela ênfase na aprendizagem. Por exemplo, o uso de filmes como uma metodologia ativa, onde se realça a aprendizagem com promoção do debate entre os discentes (BRITO, 2011), mostra a intenção por parte do docente de enfatizar a aprendizagem. Embora P2 ao tratar sobre criatividade declare não haver tido, segundo suas expressões: "Sobre criatividade, na verdade o que posso dizer sobre criatividade? Eu não fui criativa para com estes alunos [...]. Não fiz quase nada pensando nele [...]. Eu sentia dificuldades em entendê-los, entender a intérprete [...]."

A respeito da didática $\mathrm{P} 3$ coloca:

como minha disciplina que leciono é baseada em cálculos, não tive muito que alterar a minha didática, pois trabalho muito com estudo de casos, ou seja, explico a teoria e aplico exercícios. [...]. Então, pelo tipo de aula que dou, normalmente o que e que eu faço, explico a matéria, e obviamente o tradutor sempre está junto acompanhando, deixo os alunos, aspas, normais 


\section{ENSINO-APRENDIZAGEM EM CIÊNCIAS SOCIAIS APLICADAS: UM ESTUDO SOBRE EDUCAÇÃO \\ INCLUSIVA NA UNIVERSIDADE \\ DOI: http://dx.doi.org/10.5007/1983-4535.2020v13n2p49}

trabalhar e vou dar atenção para aquele aluno com necessidade especial. Tem funcionado bem assim.

Entretanto, segundo disse, sua falta de criatividade a relaciona com a falta de preparação e dessa maneira declara não ter conseguido ser criativo: "Sinto que, muitas vezes por falta de conhecimento de como lidar com esses alunos, deixamos a criatividade de lado [...]. Me preocupo se eles conseguem acompanhar as aulas. Procuro dar sempre a atenção devida, mas criativo no desenvolvimento das aulas, não fui não [...]."

No nível do seu discurso, verifica-se falta de conhecimentos extralinguísticos. Isto é, conhecimentos adequados às diferentes situações e, para isso, são importantes a imagem que faz de si e da sua posição, assim como das pessoas que vão determinar seu labor. A aprendizagem nos alunos com deficiência auditiva não é apenas um processo de aquisição de conhecimentos. As informações são importantes, mas, de acordo com os depoimentos, no processo é necessário um procedimento mais complexo, a fim dos conteúdos se tornarem compreendidos e serem significantes, para o qual a mediação é fundamental. Neste sentido, ao ser questionado, IN expressou: "Eles tem muita capacidade para aprender, entende? Mas é necessária muita atenção na hora de fazer a interpretação. Temos que ser fieis ao conteúdo para que o aluno entenda."

O processo didático, apontado por Lucarelli (2000), desenvolve-se mediante a ação recíproca dos componentes fundamentais do ensino: os objetivos da educação, os conteúdos, o ensino e a aprendizagem, os métodos, as formas e meios de organização das condições da situação didática e a avaliação.

Diante destas colocações, se observa que é necessária uma postura crítica frente à discussão acerca da educação atual, pois é preciso situar sua importância para os desafios e incertezas. Pensar em educação inclusiva e em sua prática é um dos maiores reptos hoje das instituições de ensino superior. Todos os professores deveriam estar preparados para atender às necessidades desses alunos no contexto universitário e social, compreendendo-os nas suas diferenças.

Outro aspecto a ser considerado é a participação dos intérpretes, que além da sua ação mediadora entre o professor e o aluno, determinante na compreensão dos conteúdos, colabora com os docentes dando indicações para um melhor aproveitamento no aprendizado dos alunos surdos. Nas alocuções dos professores, que adquirem sentido no contexto em que foram produzidas, se verificam algumas das ajudas dadas por eles: 
O que acontece também é que uns sabem fazer leitura labial, outros não. Assim, tenho que cuidar muito em ter que estar direcionada para ele na hora da minha fala, coisas que não tenho preocupação em uma turma sem a presença destes alunos. O intérprete sempre, aspas, nos alerta neste sentido." (P2). "Claro que, quando tem alunos deste tipo em sala de aula, tenho que observar minha posição na hora da explicação, falar com mais calma, sempre em sua direção, para que aqueles que sabem fazer a leitura labial também acompanhem. Âs vezes esqueço, mas o intérprete me orienta. (P3)

Igualmente, a participação dos intérpretes é fundamental no momento das avaliações, o que irá a ser tratado no próximo item.

\subsection{AVALIAÇÃO}

Ensinar, aprender e avaliar são fenômenos distintos, porém pertencentes a uma mesma atividade pedagógica, desta forma, ressalta Cunha (1997), a avaliação não pode ser tratada de forma isolada ou esporádica; pelo contrário, deve ser entendida como uma atividade rotineira e intrínseca à ação educativa. Nesta perspectiva, Borba e Luz (2002) colocam que a avaliação é uma tarefa didática necessária e permanente do trabalho docente, que deve acompanhar passo a passo o processo de ensino aprendizagem.

Em relação com as avaliações, as dificuldades a serem consideradas foram relatadas de maneiras diversas pelos entrevistados. P1 disse: “A prova deles já tem menos questões que os outros. Porque, como já falei, eles demoram muito mais tempo para interpretar. [...] porque o pessoal que tem a dificuldade está reclamando [...] que não estão tendo tempo para pensar, pensar as mesmas questões ainda que os outros.”

Inclusive quando P1 efetua uma revisão dos conteúdos antes das avaliações a mesma passa a estar dimensionada em função dos alunos com deficiências auditivas, como se denota na sua fala: "Em um dia de prova comentei; Oh pessoal, hoje é dia de prova, vou fazer uma revisão com menos questões por essas dificuldades."

De acordo com o exposto, entende-se que existe uma preocupação no processo de avaliação com os alunos surdos, pois este docente, que teve três alunos nessa mesma condição na turma, procurou identificar as necessidades de atenção especial e buscou adotar procedimentos que possibilitassem saná-las.

A avaliação da aprendizagem, na concepção de Abreu e Masseto (1997) é um método de adquirir e processar evidências necessárias para melhorar o ensino e a aprendizagem que inclui uma grande variedade de evidências. 
Ao se referir à avaliação, $\mathrm{P} 2$ detalha que não houve diferenças para os alunos com deficiências auditivas, manifestando-se da seguinte maneira: "Os instrumentos de avaliação eram praticamente os mesmos."

Borba e Ferri (1999) enfatizam que a avaliação é uma apreciação qualitativa sobre dados relevantes do processo de ensino e aprendizagem que auxilia o professor a tomar decisões sobre o seu trabalho. Os dados relevantes, conforme colocam as autoras, se referem às várias manifestações das situações didáticas, nas quais o docente e os discentes estão empenhados em atingir os objetivos do ensino. A apreciação qualitativa desses dados, através da análise de provas, exercícios, respostas dos alunos, realização de tarefas, entre outros, permite uma tomada de decisão para o que deve ser feito em seguida.

Sobre as avaliações, P3 declara não fazer diferenças entre os alunos ouvintes ou surdos, como mostra sua fala: “As provas e atividades são as mesmas. Não faço diferenciadas e tenho cobrado que eles resolvam [...]."

Dificilmente se encontra um professor que não se preocupe com a avaliação e na educação inclusiva os cuidados com ela devem ser mais intensos, uma vez que avaliar, na sua essência, implica num processo de julgamento. Segundo o exposto nas falas, nem todos os professores optaram por elaborar provas diferenciadas, em consideração às dificuldades de interpretação destes alunos.

Por outra parte, no processo avaliativo dos alunos com deficiência auditiva deve-se ainda considerar a participação dos intérpretes, inclusive na defesa de seu trabalho de conclusão, como IN colocou:

A sua defesa [de AG] foi algo assim que surpreendeu bastante os professores que estavam na banca. Eu diria que até excedeu as expectativas, ne? Porque eles estavam imaginando que eu ia estar por dentro da pesquisa e, de certa forma, iria colocar os resultados de uma maneira própria. Mas não [...] me limitei a fazer a tradução literal ao que o aluno colocava."

Do mesmo modo, no momento da realização de atividades avaliativas em sala de aula ou na correção que o docente vai efetuar, o intérprete tem participação. Quanto à sua presença na realização das provas $\mathrm{P} 1$ fala sobre a estranheza que isto ocasiona para os demais alunos, relatando do seguinte modo:

Daí o pessoal falou: professora, mas eles não sabem ler? Porque a intérprete fica durante a prova acompanhando, né? Daí eu falei: Eles sabem. Mas então 
professora? Respondi: Mas tem certos termos que eles não entendem, precisam de um acompanhamento, a gente tenta driblar. E ao mesmo tempo que comentaram isso, eu tenho notado que é um fator positivo, porque tem algumas coisas básicas que a gente tem que aprender né? Dividir, multiplicar, somar [neste momento a professora usava libras]. Daí tem coisas que a gente tem que falar pra eles, porque as vezes a intérprete não consegue passar.

O discurso mostra uma forma de atuar, de agir na ação educativa quando há alunos surdos, que implica na presença dos intérpretes. P1 pratica uma ação pelo ato de fala que tem por objetivo modificar uma situação.

Por sua parte, na fala de P2 se menciona uma participação diferente do intérprete durante a avaliação: "O intérprete lia a prova para este aluno e este aluno respondia e o intérprete então, colocava o X ou colocava a reposta dita pelo aluno em libras, é claro. Isso em prova."

Enquanto P3, que tinha dito que as provas eram iguais para todos os alunos independentemente da sua condição, advoga pela mínima ou a não participação do intérprete:

[...] que o intérprete não interfira, né? Às vezes não dá certo, daí o intérprete me chama e tentamos resolver o problema, mas quando é de interpretação... é difícil saber quando o que realmente está acontecendo, mas exijo que eles façam sozinhos, pois a maior parte da prova é cálculos e está bem explicado o que e como deve ser feito.

Novamente apreciam-se posições distintas entre os docentes entrevistados ao serem questionados sobre a participação do mediador durante as avaliações. As que são derivadas de seus valores e da situação que o discurso refletia, pois um docente estava ministrando uma disciplina onde havia três alunos com necessidades especiais (P1), outro tinha ministrado num outro momento (P2), o terceiro lecionava para uma turma onde apenas um estudante estava nessa condição (P3) e o quarto orientou o trabalho de conclusão do curso (P4). Já sobre a necessidade dos mediadores na interpretação ou correção da atividade avaliativa efetuada pelo aluno surdo, todos eles coincidem em não ter sido imprescindível. P1 declara que:

Em relação as correções, nunca precisei de intérprete para analisar as respostas, pois minhas disciplinas são exatas, e se tem alguma teórica, consigo entender o que escrevem, nunca precisei do auxílio dos intérpretes para corrigir as provas e demais atividades." 
Entanto P2 se manifestou assim:

Nunca tive problemas com interpretação das provas [...] sei que na construção de um texto na prova, este aluno não percebe as ligações ele só percebe as palavras, certo? O substantivo, o adjetivo e as ligações com as conjunções, preposições são dadas pelo movimento, que é a intérprete que faz, ele não tendo isto no texto, isso fica vazio, mas consigo compreender o que ele está "dizendo", sem necessitar de um intérprete na hora da correção tanto das provas, quanto das atividades.

E P3 da maneira seguinte: "Não precisei de intérprete para corrigir as atividades, pois a maior parte das questões são de cálculos e assim são resultados exatos [...]."

Finalmente, P4 não precisou de auxílio dos intérpretes para as correções: Para as correções dos relatórios parciais do Estágio, não tive nenhuma dificuldade na interpretação."

Ressalta-se que a orientação dada aos docentes é no sentido de que a avaliação pode ser diferenciada dos demais alunos ouvintes, seja no número de questões dissertativas ou no seu peso, contudo, sem alterar o conteúdo. $\mathrm{O}$ aluno entrevistado disse a este respeito: "As disciplinas todas ajudou as pessoas desenvolver. As atividades cobradas na turma ajudo desenvolver competências e fazer habilidades."

Na resposta sobre avaliação junto ao grupo e com a participação do mediador, nota-se que o aluno se sente incluído no processo de formação universitária.

\subsection{ORIENTAÇÕES PEDAGÓGICAS}

O cotidiano da prática profissional dos professores, segundo Borba e Luz (2002), é constituído de contradições pela imprevisibilidade das relações que se estabelecem nas situações de trabalho, gerando conflitos e inquietações, as quais submetidas à reflexão e sendo compartilhadas, podem indicar novas alternativas para a compreensão da lógica do processo de aprendizagem. Os estudos na área de formação de docentes têm evidenciado que sua profissão é construída pela mobilização de experiências e conhecimentos vivenciados no contexto do seu trabalho.

Com o intuito de analisar os aspectos formativos se entrevistou à orientadora pedagógica (OP) do Centro de Ciências Sociais Aplicada. Ao ser questionada sobre quais ações precisariam ser desenvolvidas na seção sob sua responsabilidade para programar as atividades que requerem os alunos com necessidades especiais, particularmente, as deficiências auditivas, OP respondeu: “[...] a gente precisa de um acompanhamento 
constante com os professores, né? Até por uma questão de [...] de [...] de orientação, porque a gente eh... eh... busca sempre dizer a eles que eles têm que ser tratados de uma maneira especial, mas não diferentes [...]."

A fala parece refletir uma busca por intenções implícitas na pergunta formulada, pois a legislação pressupõe que o corpo docente possua o preparo adequado e, nesse sentido, a seção pedagógica do Centro tem sua parcela de responsabilidade. Isto é assim porque as orientações também são dadas por outra área da universidade. Os professores recebem indicações de diversas fontes, conforme a OP expressa:

A gente busca sempre essa orientação ou então, no início dos semestres a gente tem a relação que vem do $\mathrm{PADEF}^{3}$ para os alunos com necessidades especiais, elas acompanham a matrícula de como orientar os professores, então vem o material da Pró-reitoria de ensino que busca, na verdade, dar um direcionamento, nós lemos o acompanhamento do PADEF com a professora Cinara que também vem, conversa com os professores e dá toda essa orientação para que os alunos tenham um desempenho satisfatório e que não sejam prejudicados por esta condição que eles tenham.

Nota-se na fala de OP o caráter heterogêneo do seu discurso, que dialoga com outras visões. Segundo Lucarelli (2000), a formação não se constrói por acumulação de cursos, conhecimentos e técnicas, mas sim, através de um trabalho de reflexividade crítica sobre práticas e de reconstrução permanente da identidade pessoal. Seguindo o pensamento deste autor, Zeichner (2003) enfatiza o valor do contexto, chamando a atenção para que o professor seja levado não só a refletir sobre seu labor, mas a analisar e entender as condições sociais, políticas e econômicas que interferem em sua prática pedagógica.

Por outra parte, com relação à busca de apoio por parte dos professores que tiveram na turma algum aluno com necessidades auditivas OP declara:

Os professores buscam comigo esclarecer dúvidas, o que a gente não sabe busca também com a fonoaudiologia e a Professora Cinara, as orientações até como lidar porque tem uma terceira, uma mediação entre o professor, o intérprete de libras e vai ai também que é um terceiro envolvido no processo de ensino-aprendizagem e até onde o intérprete pode ir ou então, a gente também, essas dúvidas que a gente trabalha junto ao PADEF.

As experiências adquiridas pelos professores que lecionaram para turmas onde houve algum aluno com deficiência auditiva induzem a estes profissionais à uma reflexão sobre seu trabalho docente e sobre sua preparação. A formação para Perrenoud (2001) deve estimular uma perspectiva crítico-reflexiva, que forneça aos professores os meios de um pensamento 
autônomo. Estar em formação implica em um desenvolvimento pessoal, um trabalho livre e criativo sobre os percursos e os projetos próprios, com vista à construção de uma identidade, que é também uma identidade profissional.

A partir desta perspectiva, Zeichner (2003) destaca que se extingue o conceito de formação docente como processos de atualizações que ocorrem através da aquisição de informações didáticas, científicas e psicopedagógicas, descontextualizadas da prática educativa do docente, para elaborar um conceito que consiste em construir conhecimentos e teorias sobre a prática docente, a partir da reflexão crítica.

Nesse sentido, ao tratar das relações que se devem estabelecer entre docentes e discentes com incapacidade auditiva, para serem harmoniosas e adequadas, OP disse:

[...] não sei se seriam bem habilidades, sabe, eu acho que é muito uma questão de atitude, é lidar diferente e., como comentei ... é ter a consciência que exige um tratamento especial mas não diferenciado, né? Então é muito uma questão de tratar de maneira igual para não ter um tratamento diferente, por isso que acho que é mais uma questão de atitude.

Há na alocução da OP um posicionamento definido pelas suas próprias crenças, porém, a preocupação principal na formação por parte da seção pedagógica do Centro parece estar mais vinculada aos procedimentos nas aulas que no desenvolvimento de atitude reflexiva, como se depreende de outras partes do discurso de OP:

Para o próximo semestre, estamos incluindo na nossa formação continuada, uma oficina sobre comportamento. Que comportamento a gente tem que ter para passar para os professores, desde uma postura diferenciada em sala de aula. Isto que queremos trabalhar com os professores, de buscar orientá-los que é um pouco diferente. Assim, vai ter uma oficina na formação continuada. O pessoal do PADEF trabalhará conosco sobre os limites, adaptações de aulas, conteúdos que a gente tem que ter, postura na hora das aulas dialogadas, algumas adaptações com o material, importância do intérprete nesta relação professor $\mathrm{x}$ intérprete $\mathrm{x}$ aluno.

Diante destas colocações, deve ser observado que a postura reflexiva não requer apenas do professor o saber fazer, mas que ele saiba explicar de forma consciente as suas práticas e as decisões tomadas e perceber se são as melhores para favorecer a aprendizagem discente, pois segundo Perrenoud (2001), ensinar é, antes de tudo, agir na urgência, decidir na incerteza. 


\section{CONSIDERAÇÕES FINAIS}

Neste estudo trataram-se três assuntos considerados essenciais para o bom desenvolvimento da formação universitária, quando entre os discentes há um ou mais que apresente deficiência auditiva. Assim as adaptações ao plano de ensino, nos procedimentos didáticos e nas avaliações são necessárias à observação da legislação e por isso se escolheram.

Todos os docentes entrevistados declararam ter feito adaptações no plano de ensino, mas sem mudanças nos conteúdos. Entretanto, se manifestam dúvidas quanto à qualidade do ensino no geral, por exemplo, devido ao menor número de atividades práticas, conforme relato de um dos professores, ou pelas facilidades dadas apenas aos surdos de fazer atividades em dupla.

Quanto aos procedimentos didáticos empregados também todos mencionaram ter feito adequações, mas é neste tema onde se encontram diferenças nas descrições, pois se depreende das falas que as mesmas foram desde muito superficiais até profundas.

Ao se trabalhar o tema das avaliações, novamente se constata diferença entre os respondentes. Enquanto um disse não fazer mudanças nas provas dos alunos surdos os outros docentes as fizeram. Do mesmo modo acontecem divergências entre os professores quando se trata da participação dos intérpretes. No entanto, um busca restringir ao máximo, outros são mais permissivos, mas todos eles declaram não precisar dos mediadores na hora das correções das provas ou atividades. Isto implica em que os alunos deficientes adquiriram conhecimentos, obviamente com o auxílio dos intérpretes, e souberam expressá-los.

As análises das orientações pedagógicas que são dadas aos professores claramente se podem considerar como procedimentais, simples recomendações de como proceder nas aulas. A preocupação com as dificuldades enfrentadas por aqueles docentes que tenham que lecionar para turmas onde participe um ou mais discentes surdos tem levado a se pensar numa ação específica formativa e para tanto realizar uma oficina durante as formações continuadas que a instituição propicia para todos os seus docentes.

Ao modo de conclusão cabe dizer que os preceitos da legislação são parcialmente atendidos, pois segundo consta na Lei de Diretrizes e Bases da Educação Nacional, Lei Federal $n^{\circ}$ 9.394, as instituições, além de possuir um trabalho pedagógico específico que atenda ao portador da deficiência, devem contar com professores capacitados. E isto não se constata de maneira integral no estudo desenvolvido. 
Finalmente, cabe fazer sugestões no intuito de contribuir no melhoramento do processo. Inicialmente, considera-se necessário fazer um levantamento de todos os problemas que sejam mencionados pelos professores que já tenham passado por uma experiência de ministrar aulas para turmas onde houve algum deficiente auditivo. Essas informações das práticas docentes, mais os embasamentos teóricos existentes, permitiriam desenhar futuramente uma oficina que seja realmente formativa e ajustada à realidade local, pois é a reflexividade crítica que haverá de superar o meramente procedimental.

Outra sugestão é realizar capacitações conjuntas de professores e intérpretes, onde sejam debatidas as dificuldades e possíveis soluções quando não há condição de dispor de um intérprete que tenha formação específica no curso onde atua. Todavia, se considera importante complementar este estudo inicial com outros que envolvam aos alunos sem deficiências e aos outros órgãos institucionais que também tratam desta problemática.

\footnotetext{
Notas

[1] Denomina-se deficiência auditiva a diminuição da capacidade de percepção normal dos sons, sendo considerado surdo o indivíduo cuja audição não é funcional na vida comum, e parcialmente surdo, aquele cuja audição, ainda que deficiente, é funcional com ou sem próteses auditivas.

[2] É o Ambiente Virtual de Aprendizagem da universidade onde se desenvolveu o trabalho.

[3] O Programa de Atenção aos Discentes, Egressos e Funcionários - PADEF desenvolve metodologias de atendimento aos discentes com necessidades educacionais especiais, incluindo acompanhamento psicopedagógico em sala de aula a alunos do Colégio de Aplicação e dos cursos de graduação. Também presta orientação a professores, pais e familiares dos alunos atendidos, favorecendo a inclusão de pessoas com deficiências visual, auditiva, intelectual, física, dentre outras.
}

\section{REFERÊNCIAS}

ABREU, M. C. de; MASETTO, M. T. O professor universitário em aula: prática e princípios teóricos. São Paulo: Cortez, 1997.

ALENCAR, E. M. L. S. Tendências atuais e desafios da educação especial. Brasília: MEC, 1994. (Série atualidades pedagógicas).

BAUER, M. W. Análise de conteúdo clássica: uma revisão. In: Bauer MW, Gaskell G. Pesquisa qualitativa com texto, imagem e som: um manual prático. 3. ed. Petrópolis: Vozes, 2002

BONGARRÁ, C. La universidad y la inclusión de los sordos. Reflexión Académica en Diseño y Comunicación, Ano IX. v. 9, p. 74-78, 2008.

BORBA, A. M. de.; FERRI, C. Avaliação: contexto e perspectiva. In: CAPELLETTI, I. (org.). Avaliação educacional: fundamentos e práticas. São Paulo: Articulação Universidade/Escola, 1999. 
BORBA, A. M. de; LUZ, S. P. da. Formação continuada para docentes do ensino superior: apontamentos para novas alternativas pedagógicas. Cadernos de ensino. Itajaí: Ed. UNIVALI, 2002.

BORDENAVE, J. D.; PEREIRA, A. M. Estratégias de ensino aprendizagem. Petrópolis: Vozes, 1995.

BOTELHO, P. Linguagem e letramento na educação dos surdos: ideologias e práticas pedagógicas. Belo Horizonte, Autêntica, 2002.

BRASIL. Lei Federal nº 9.394 de 20 de dezembro de 1996. Estabelece as diretrizes e bases da educação nacional.

BRASIL. Decreto $n^{\circ} 3.298$ de 20 de dezembro de 1999. Regulamenta a Lei no 7.853 , de 24 de outubro de 1989, dispõe sobre a Política Nacional para a Integração da Pessoa Portadora de Deficiência, consolida as normas de proteção, e dá outras providências.

BRASIL. Lei Federal no 10.436 de 24 de abril de 2002. Dispõe sobre a Língua Brasileira de Sinais - Libras e dá outras providências.

BUENO, J. G. S. Educação inclusiva e escolarização dos surdos. Integração, n. 23, p. 37-42, 2001.

BRITO, L. F. Por uma gramática de línguas de sinais. Rio de Janeiro: Ed. Tempo Brasileiro, UFRJ, 1995.

BRITO, M. H. Applying films on environmental cases to discuss corporate response end ethics. In: Anais ... III Encontro de Ensino e Pesquisa em Administração e Contabilidade EnEPQ, 2011.

CARDOSO, G. M. R. Departamento com surdo. Rio de Janeiro, 2001. Disponível em: http://www.deptosurdos.hpg.ig.com.br/apresentacao.htm. Acesso em: 15 abr. 2018.

CUNHA, M. I da. Aula universitária: inovação e pesquisa. In: LEITE, Denise B. C; MOROSINI, M. (orgs). Universidade futurante: produção do ensino e inovação. Campinas: Papirus, 1997, p. 79- 93. (Coleção Magistério: Formação e Trabalho Pedagógico).

GIORDANI, E. M. A docência como ato de inteligência e a formação do professor universitário. In: Anais... I Fórum de Ensino Superior do Sudoeste do Paraná e Oeste de Santa Catarina. Pato Branco, CEFET, Fundação Araucária, 2002.

GODOY, A. S. Pesquisa qualitativa: tipos fundamentais. Revista de Administração de Empresas, v. 35, n. 3, p. 20-29, 1995.

HERRÁN, A. G. Contribución al concepto de creatividad: um enfoque paquidérmico $\left(3^{\mathrm{a}}\right.$ parte). Educación y Futuro, v. 23, p. 131-162, 2010. 
IBGE - INSTITUTO BRASILEIRO DE GEOGRAFIA E ESTATISTICA. Censo demográfico. Disponível em: http://www.ibge.gov.br Acesso em: 10 abr. 2018

LACERDA, C. B. F.; POLETTI J. E. A escola inclusiva para surdos: a situação singular da intérprete de língua de sinais. ANPED, 2004. Disponível em:

http://www.anped.org.br/reunioes/27/gt15/t151.pdf. Acesso em: 25 set. 2018.

LIBÂNEO, J. C. Didática. São Paulo: Cortez, 1991.

LUCARELLI, E. Um desafio institucional: inovação e formação pedagógica do docente universitário. In: CASTANHO, S.; CASTANHO, M. O que há de novo na educação superior: do projeto pedagógico à prática transformadora. Campinas: Papirus, 2000.

MAINGUENEAU, D. Gênese dos discursos. São Paulo: Parábola Editorial, 2008.

MERRIAM S. Qualitative Research and Case Study Applications in Education. San Francisco: Jossey-Bass Publishers, 1998.

MEC - MINISTÉRIO DE EDUCAÇÃO E CULTURA. Declaração de Salamanca sobre princípios, políticas e práticas na área das necessidades educativas especiais. Disponível em: http://portal.mec.gov.br/seesp/arquivos/pdf/salamanca.pdf. Acesso em: 25. ago. 2018.

OLIVEIRA, M. M. Como fazer pesquisa qualitativa. Petrópolis: Vozes, 2007.

ONU - ORGANIZAÇÃO DAS NAÇÕES UNIDAS. Convention on the rights of persons with disabilities. Disponível em:

http://www.un.org/disabilities/convention/conventionfull.shtml Acesso em: 25. maio 2018.

PERRENOUD, P. La formación de los docentes en el siglo XXI. Revista de Tecnología Educativa, v. 14, n. 3, p. 503-523, 2001.

QUADROS, R. M. de. As categorias vazias pronominais: uma análise alternativa com base nas LIBRAS e reflexos no processo de aquisição. Dissertação de Mestrado. PUCRS. Porto Alegre, 1995.

SKLIAR, C. Educação e exclusão: Abordagens sócio-antropológicas em educação especial. Porto Alegre: Ed. Medicação, 1997.SOARES, M. A.L. A educação do surdo no Brasil. Bragança: Autores Associados, EDUSP, 1999.

TEODORO, A.; VASCONCELOS, M. L. Ensinar e aprender no Ensino Superior, por uma epistemologia da curiosidade na formação universitária. São Paulo: Cortez. 2003.

ZEICHNER, K. M. Formação de professores reflexivos para a educação centrada nos alunos: possibilidades e limites. In: BARBOSA, R. L. L. (Org.). Formação de educadores: desafios e perspectivas. São Paulo: UNESP. 2003. 